\title{
INTERNACIONALIZAÇÃO DE PERIÓDICOS CIENTÍFICOS BRASILEIROS: ESTUDO DE CASO À LUZ DA TEORIA DE REDES E DA TEORIA INSTITUCIONAL
}

\section{RESUMO}

Esse artigo questiona sobre o desafio da internacionalização dos periódicos científicos brasileiros da área de Administração. O objetivo desse artigo, é analisar como duas teorias, que na última década ganharam grande espaço para explicar a internacionalização de empresas, a saber, a teoria das redes e institucional, ajudam a compreender a internacionalização dos periódicos, e como a análise do fenômeno da internacionalização dos periódicos levanta novas proposições para o processo de internacionalização, quando analisado por essas duas perspectivas teóricas. A fundamentação teórica está embasada na teoria de redes, e no ambiente institucional. Por meio de uma metodologia de pesquisa qualitativa, buscou-se entender qual é a inserção da revista na rede e qual é a compreensão que o editor tem em relação ao ambiente institucional e como esse entendimento conduz ao processo de internacionalização. Percebe-se, como resultado, uma forte pressão do ambiente institucional do país de origem e uma baixa inserção dos periódicos nas redes. Os resultados levantam o desafio de uma política articulada das instituições dos países de origem e sobre a internacionalização dos periódicos. Isso edifica a importância de uma intersecção entre a teoria do ambiente institucional combinada com a teoria das redes de negócios para explicar o movimento de internacionalização de unidades de negócios, a saber, os periódicos acadêmicos.

Palavras-chaves: Internacionalização; Periódicos científicos; Teoria institucional; Teoria das redes.

\section{INTERNATIONALIZATION OF BRAZILIAN SCIENTIFIC JOURNALS: CASE STUDY IN LIGHT OF THE NETWORK THEORY AND THE INSTITUTIONAL THEORY.}

\begin{abstract}
The article questions the challenges of internationalization of Brazilian scientific journals in the administration area. The aim of this paper is to analyze how two theories, that over the past decade gained great space to explain the internationalization of companies, namely the theory of networks and institution, to help us understand the internationalization of the journals, and how the analysis of the phenomenon of globalization of journals raises new proposals for the internationalization process when analyzed by these two theoretical perspectives. The theoretical framework is based on the network theory, and on the institutional environment. By means of a qualitative research methodology, we attempted to understand what the journal's inclusion in the network is and what understanding the publisher has in relation to the institutional environment and how this understanding leads to the internationalization process. One perceives as a result a strong pressure from the institutional environment from the country of origin and a low rate of inclusion of journals in networks. These results raise the challenge of an articulated policy of the institutions from the countries of origin and internationalization of the journals. This builds up the importance of an intersection between the theory of the institutional environment combined with the theory of the business networks to explain the business units internationalization movement, namely, academic journals.
\end{abstract}

Keywords: Scientific Journals; internationalization; Institutional theory; Network Theory. 


\section{INTERNACIONALIZACIÓN DE REVISTAS CIENTÍFICAS BRASILEÑAS: ESTUDIO DE CASO A LA LUZ DE LA TEORÍA DE LA RED Y LA TEORÍA INSTITUCIONAL.}

\section{RESUMEN}

El artículo cuestiona los retos de la internacionalización de las revistas científicas brasileñas en el área de administración. El objetivo de este trabajo es analizar cómo dos teorías, que en la última década ganaron gran espacio para explicar la internacionalización de las empresas, al saber la teoría de las redes y la institución, para ayudarnos a entender la internacionalización de las revistas, y cómo el análisis del fenómeno de la globalización de las revistas plantea nuevas propuestas para el proceso de internacionalización cuando se analiza por estas dos perspectivas teóricas. El marco teórico se basa en la teoría de la red, y en el ambiente institucional. A través de una metodología de investigación cualitativa, se intentó comprender lo que la inclusión de la revista en la red y lo que la comprensión de la editorial tiene en relación con el entorno institucional y cómo esta comprensión conduce al proceso de internacionalización. Se percibe como resultado una fuerte presión del entorno institucional del país de origen y una baja tasa de inclusión de revistas en las redes. Estos resultados plantean el reto de una política articulada de las instituciones de los países de origen y la internacionalización de las revistas. Esto se acumula en la importancia de una intersección entre la teoría del entorno institucional combinada con la teoría de las redes de negocios para explicar el movimiento de internacionalización de las unidades de negocio a saber, las revistas académicas.

Palabras clave: Revistas Científicas; internacionalización; Teoría institucional; Teoría de Redes.

\footnotetext{
${ }^{1}$ Doutor em Administração pela Faculdade de Economia, Administração e Contabilidade da Universidade de São Paulo - FEA/USP. Professor da Escola Superior de Propaganda e Marketing - Espm e da Faculdade de Economia, Administração e Contabilidade da Universidade de São Paulo - FEA/USP. Brasil. E-mail: fborini@espm.br

${ }^{2}$ Mestre em Administração pela Escola Superior de Propaganda e Marketing, Brasil - Espm. Assistente Editorial da Escola Superior de Propaganda e Marketing - Espm. Brasil. E-mail: jac@espm.br
} 


\section{INTRODUÇÃO}

A produção científica brasileira nos últimos anos vem apresentando plena ascensão em termos de quantidade (Packer, 2011), superando países como Holanda, Israel e Suíça (Regalardo, 2010). Tal crescimento deve-se, em parte, pelo crescimento da pós-graduação no país (SandesGuimarães, 2013). Outro fator que contribui para a expansão da publicação científica é a reestruturação na avaliação dos cursos de pós-graduação engendrada pela Capes, pois, a cada triênio (doravante quadriênio), aumenta no peso da avaliação $\mathrm{o}$ aspecto relacionado à produção bibliográfica qualificada (Nascimento e Salvá, 2013). Ao analisar a área de Administração, principal objeto deste estudo, constata-se a mesma evolução tanto dos programas quanto dos periódicos científicos.

No entanto, o desafio da produção científica brasileira não se limita ao volume de artigos produzidos. O problema está na veiculação de artigos qualificados. De um lado, os pesquisadores nacionais precisam aumentar a inserção de sua produção em periódicos internacionais, e, de outro lado, os periódicos nacionais precisam melhor se qualificar para aumentar sua inserção internacional. Quando se trata da prerrogativa produção científica “[...]um dos critérios considerados mais relevantes é o grau de sua internacionalização" (Fiorin, 2007, p. 264). Entre os Brics (Brasil, Rússia, Índia, China e África do Sul), o Brasil é pouco internacionalizado, tanto que ficou à frente somente da África do Sul (Alisson, 2013) sendo que, pesquisadores brasileiros são citados, em sua maioria, somente em periódicos nacionais (Costa et al, 2012), o que afirma a dificuldade dos pesquisadores de publicar em periódicos internacionais (Meneghini, 2012). Alisson (2012) informa que grande parte das revistas brasileiras indexadas em bases internacionais publica em torno de $85 \%$ dos artigos de autores locais. A colaboração internacional não ultrapassa os $8 \%$. Na área de Administração, poucos são os periódicos internacionalizados e, quando o são, estão muito restritos a uma indexação recente nos índices Journal Citation Reports (JCR) ou Hindex (índice $\mathrm{H}$ da base Scopus). Contudo, mesmo esses sofrem da baixa citação não local e da baixa participação de artigos escritos por não brasileiros.

Diante disso, esse artigo questiona sobre o desafio da internacionalização dos periódicos científicos brasileiros da área de administração. Ancorado em duas teorias que ganharam espaço no campo dos negócios internacionais nas últimas décadas, a saber a teoria das redes e institucional, pergunta-se, como a inserção dos editores, nas redes interorganizacionais de seu campo, e a pressão percebida referente ao ambiente institucional, influenciam a internacionalização dos periódicos brasileiros da área da Administração de Empresas? Desse modo, o objetivo desse artigo é explicar, à luz da teoria institucional e da teoria de redes sociais, o fenômeno da internacionalização de periódicos científicos brasileiros, na área da Administração de Empresas. A proposição que norteia o artigo é que a internacionalização dos periódicos científicos brasileiros da área de administração é dependente das pressões institucionais, assim como da inserção das revistas nas redes interorganizacionais. Isso edifica a importância de uma intersecção entre a teoria institucional combinada com a teoria das redes para explicar o movimento de internacionalização dos periódicos acadêmicos.

A metodologia desenvolvida para esse trabalho foi pautada na abordagem qualitativa, por meio do método "estudo de caso". O estudo empírico foi realizado com seis revistas acadêmicas, classificadas pelo WebQualis nos estratos B1 e B2 na área de Administração em 2014. Das revistas selecionadas, três eram do estrato B1 e as outras três do estrato B2. As entrevistas foram realizadas com os editores chefes dos periódicos e trianguladas com a análise documental dos periódicos em questão.

\section{REFERENCIAL TEÓRICO}

A internacionalização de uma organização ocorre quando a mesma passa a ter seus bens representados ou vendidos em mercados externos (Cavusgil, Knight, Riesenberger, 2010). Ao considerarmos um periódico cientifico como uma unidade organizacional é necessário refletir sobre o que significa sua internacionalização. $\mathrm{O}$ periódico ser vendido no exterior não representa a melhor maneira de entender sua internacionalização. Assim, inicialmente, é necessário explicar o que, neste texto, é considerado a internacionalização de um periódico científico.

A internacionalização dos periódicos pode ser analisada por três direções: A primeira, seria a hospedagem das revistas nacionais em publishers internacionais de grande influência (Himura et. al, 2014; Trzesniak, 2000). Uma segunda via seria a internacionalização autoconduzida, sem fazer parte de uma grande editora, mas procurando enquadrar os periódicos nas bases de dados abertas como o Scielo e Redalyc (Packer, 2015). Uma terceira via da internacionalização consiste na obtenção da indexação em bases, tais como a Thomson Reuters 
(JCR) e Scopus (H-index). Não necessariamente a revista precisa ser de um publisher ou seguir as normas da Scielo, mas as duas alternativas ajudam nesse processo, uma vez que a indexação é impulsionada pela maior visibilidade internacional e citação de artigos da revista em periódicos indexados nesses dois índices.

Tanto a primeira, quanto a segunda e a terceira alternativa de internacionalização estão alinhadas com as diretrizes de internacionalização dos periódicos científicos estipuladas pela Coordenação de Aperfeiçoamento de Pessoal de Nível Superior (Capes). Portanto, entendemos nesse artigo que, um periódico científico internacionalizado seria aquele que ultrapassa as fronteiras nacionais não só em termos de distribuição ou venda dos seus artigos, mas por meio da inserção internacional em seu conselho editorial, comitê editorial e cientifico, pareceristas e autores. Para tanto, a percepção que o editor tem da pressão do ambiente institucional e sua inserção na rede internacional de pesquisadores é essencial para conduzir o periódico rumo a internacionalização.

\subsection{A pressão do ambiente institucional para a internacionalização dos periódicos}

As pressões dos mecanismos institucionais coercitivos, normativos e miméticos (Dimaggio, Powell, 2005, Scott, 1995) exercem influência na internacionalização das empresas, seja ao considerar as instituições no país de origem ou hospedeiro. As instituições dos países de origem moldam, em grande parte, as vantagens e desvantagens das organizações em seus processos de internacionalização (Cuervo-Carzurra, Genc, 2011). Por outro lado, as instituições do país hospedeiro imprimem forte pressão quanto a capacidade competitiva da empresa, fator conhecido como a liability of foreigness, doravante chama de desvantagem de ser estrangeiro (Kostova, Zaher, 1999). A empresa, ao atuar em mercados internacionais, sofre dessa desvantagem perante os competidores nacionais em razão de sua baixa adaptação inicial as instituições locais. Dessa forma, subjugada aos mecanismos institucionais coercitivos e normativos, a empresa procura ao máximo se adequar as normas locais e, por vezes, parcialmente ou inteiramente, embrenha-se em estratégias de mimetismo às organizações locais para diminuir o máximo possível essa desvantagem de ser estrangeiro (Salomon, Wu, 2012). Fator esse que, por vezes, é por demais dificultado devido as grandes distâncias institucionais (Berry, Guileen, Zhou, 2010), em especial quando a organização advém de um mercado emergente para competir em um mercado desenvolvido (Contractor, 2013).
Ao transpormos a questão da pressão institucional para o âmbito dos periódicos acadêmicos, identificamos os desafios da internacionalização nas duas pontas, ou seja, no país hospedeiro e no país de origem.

No país de origem, em especial em relação ao aspecto normativo, os periódicos acadêmicos, para serem estratificados, devem cumprir a normatização estabelecida pela Capes. Eles não deixam de existir se não cumprirem as normas, mas são classificadas nos estratos mais baixos, ou nem classificadas. Ademais, essa mesma normatização da Capes classifica a revista como um veículo de maior ou menor impacto conforme a sua classificação no estrato. Sendo que essa classificação atua como um instrumento normativo que impele o movimento de internacionalização das revistas, uma vez que, para figurar nos extratos mais elevados na classificação Web-qualis, deve possuir indexação internacional, como, por exemplo, indexadores Thompson Reuters e Scopus. Sobre a premissa de que uma revista indexada é uma revista de qualidade, Packer (2011) e Trzesniak et al (2012) acrescentam que pertencer aos indexadores, além de promover a visibilidade, conduz também ao prestígio do periódico.

Ainda no campo normativo, existe, também, a pressão institucional aos PPGs Programas de Pós-Graduação - e aos docentes vinculados a esses programas (Mattos, 2008; Rosa, 2008). Em busca da excelência na pontuação e de ter uma boa avaliação da Capes, os programas, cada vez mais incentivam os docentes a publicarem seus trabalhos em periódicos classificados em altos estratos, estes, por sua vez, indexados na Thompson Reuters ou Scopus. Desse modo, em razão das pressões exercidas no contexto da pós-graduação stricto-sensu no curso de Administração, as revistas, com o objetivo de ter melhor visibilidade acadêmica e atrair as melhores publicações em parâmetro global, precisam se internacionalizar em busca da indexação, pois caso contrário serão preteridas para ser o veículo das principais publicações dos pesquisadores brasileiros e internacionais.

Ainda, quanto aos mecanismos de pressão isomórfica no país de origem, podemos destacar a forte pressão normativa e cognitiva para uma padronização dos periódicos. Dado que o modelo de excelência proposto pela Capes são as revistas de maior classificação nos estratos, e que elas são as que atraem mais e os melhores trabalhos dos pesquisadores, é fácil verificar que essas revistas acabam sendo referências para aquelas que desejam alcançar maior classificação. Desse modo, existe na área da editoração científica em Administração uma pressão mimética (Scott, 1995) dos periódicos de 
menor estrato copiarem os de maior estrato. O desejo dos editores das revistas em elevar o seu estrato, conduz os mesmos a acompanharem as ações das revistas nos melhores estratos.

Outro motivo que leva à padronização das revistas é a adoção do manual de boas práticas científicas elaborado pela Anpad. Nele, encontramse recomendações de procedimentos operacionais e estratégicos que um periódico científico na área de Administração deve cumprir para a obtenção de melhores estratos, assim como, a indexação em bases de dados estratégicos. Além disso, seguir esse Manual, por exemplo, é recomendado para que a revista entre no Spell. Por fim, outro sistema de padronização é a adoção do Sistema Eletrônico de Editoração de Revistas (Seer). No Brasil, o sistema é viabilizado pelo Instituto Brasileiro de Informação e Tecnologia (Ibict), tornando-se uns dos maiores divulgadores e fornecedores de treinamento para essa ferramenta. Por ser um sistema de acesso aberto e gratuito, facilita a adoção do sistema. Por fim, mas não menos importante, temos a recente iniciativa do Spell, que permite somente a participação de revistas em sistemas eletrônicos e que sigam padrões determinados pela base.

Desse modo, ao analisar a pressão institucional do país hospedeiro e a busca da internacionalização do periódico científico brasileiro para vencer a desvantagem de ser estrangeiro, o cenário denota uma estratégia passiva dos periódicos e longe de superar a desvantagem de ser estrangeiro. Primeiro, quanto ao idioma, verifica-se que não chega a uma dezena o número de periódicos na área de Administração que publicam em inglês, seja porque adotam esse idioma como a oficial ou porque traduzem os artigos. Uma vez que o idioma inglês é o adotado pelos principais periódicos da área e maior parte dos periódicos indexados pela Thomson ou Scopus, o fato de permanecer com o idioma português como língua oficial já constitui uma grande desvantagem. Além disso, verifica-se que os periódicos nacionais não versam a respeito de nenhum tema específico que represente uma lacuna ou uma expertise advinda de países em desenvolvimento para garantir sua inserção no mercado global. Isso denota a falta de preocupação de um posicionamento ancorado numa vantagem competitiva advinda da desvantagem de ser uma nação não desenvolvida (Cuervo-Carzurra, Genc, 2011). Decorrente disso, é plausível questionar porque um pesquisador que tem um bom artigo escolheria uma revista genérica de Estratégia, Marketing, Produção, etc., brasileira, se já existe periódicos internacionais consolidados na área. Eis, outro ponto que denota a desvantagem dos periódicos nacionais, perante a academia internacional, o periódico brasileiro é genérico, é só mais um dentre tantos, e não se diferencia.

Dessa forma verifica-se que, no campo dos periódicos de Administração, existe uma forte pressão institucional mimética e normativa que impulsiona o movimento de internacionalização das revistas, porém uma ausência da estratégia de superar a desvantagem de ser estrangeira. Logo, percebe-se que a internacionalização dos periódicos de administração é um processo decorrente da pressão do ambiente institucional do país de origem e não de uma estratégia deliberada dos periódicos de atuar no exterior. Consequentemente, é necessário refletir como que os periódicos podem responder a essa pressão institucional. Ao que tudo indica, pelo próprio modelo de internacionalização apoiado pela Capes e ratificado pelos PPGs, por meio da indexação, ou vinculação a um Publisher, ou ainda, atendimento das regras do Scielo, a pressão institucional induz uma forte necessidade para o periódico se inserir em redes de pesquisadores internacionais.

\subsection{A inserção nas redes e a internacionalização dos periódicos acadêmico}

Desde que o modelo de Uppsala (Johanson e Vahlne, 1977) foi proposto no final da década de 1970, constatou-se que ocorreram várias mudanças no ambiente de negócios internacionais, e, em função dessas mudanças, Johanson e Vahlne (2009) propõem um modelo revisitado visando a contribuir para uma melhor compreensão das complexidades existentes nos mercados e que permitem explicar o processo de internacionalização.

Johanson e Vahlne (2009) entendem o processo de internacionalização por meio da perspectiva das redes, desse modo, propõem que a estratégia de internacionalização decorre do desenvolvimento dos relacionamentos. Neste contexto, a empresa para ser bem estabelecida em um processo de internacionalização, além de pertencer a uma ou mais redes que permitiram a aprendizagem local, ela deve ter uma posição relevante dentro da rede, o que permitirá não só aprendizado, mas, também, a construção de confiança e comprometimento, assegurando, assim, as condições para a internacionalização. Já a falta de uma posição relevante em uma rede denominase outsidership. A empresa que deseja ingressar em um mercado estrangeiro e encontra-se em uma posição não relevante na rede, provavelmente sofrerá liability of outsidership (desvantagem de não fazer parte da rede), dificultando o seu ingresso e a possibilidade de se tornar relevante (Johanson e Vahlne, 2009). 
Assim, conforme Johanson e Mattsson (1988) e Johanson e Vahlne (2009), a internacionalização, por meio de redes, pode ser alcançada por meio de três etapas: (1) o estabelecimento de relacionamentos em redes de países que sejam novos para a empresa, (2) reforço no comprometimento e desenvolvimento cujos relacionamentos externos já foram estabelecidos e (3) coordenação entre as redes de diferentes países, qual seja, a integração. Todo o conjunto de relacionamento que a empresa possui é considerado como ponte para o acesso a outras redes, até mesmo as redes pessoais são facilitadoras para as redes internacionais.

Desse modo, pensando na internacionalização da revista, é essencial discutir a questão dos relacionamentos da revista como forma de internacionalização. Neste ponto, destaca-se o papel central que o editor do periódico desempenha na articulação dos relacionamentos e no papel de enxergar oportunidades oriundas da rede.

Cabe ao editor articular os relacionamentos com o conselho ou comitê científico, corpo editorial científico, consultores ad hoc e editor científico, de modo a atrair membros internacionais e de renome no campo de atuação para fazer parte da rede, superando parcialmente a desvantagem de não fazer parte da rede. Se o editor tem e consegue estabelecer laços além das fronteiras nacionais, ele consegue atrair editores científicos, membros do conselho, avaliadores para sua revista, que, por sua vez, esses membros podem usar suas redes para divulgar a revista e atrair autores internacionais. Desse modo, os relacionamentos que o editor e seu corpo editorial estabelecem ajuda ao periódico a ser reconhecido e, talvez, ser escolhido pelos autores da área. Se isso acontece, são atendidas as pressões do Scielo para ter autores internacionais, as pressões dos indexadores para ter citação e a pressão da CAPES e PPGs para ter maior inserção internacional.

Partindo dos estudos de Balkundi e Kilduff (2006), o editor somente conseguirá exercer esse papel se tiver uma estruturada relação social e capital social, assim como uma posição de pertença e de centralidade na rede. Primeiro, porque os relacionamentos do editor é que irão acessar o corpo editorial responsável pelo funcionamento e pela qualidade da revista. Um editor com relacionamentos mais profícuos com membros da comunidade acadêmica internacional terá mais possibilidade de atrair esses para seu corpo editorial. Segundo, esse editor, para atrair os melhores recursos humanos para seu time editorial, precisa ter uma inserção no campo de pesquisa da revista. Logo, espera-se que o editor seja um membro atuante e reconhecido dentro da comunidade acadêmica nacional e internacional. Terceiro, o capital social que esse editor construiu em sua trajetória de pesquisador será essencial para reunir e conduzir o corpo da revista, assim como para dar legitimidade ao periódico. Por último, a posição que esse editor ocupa no cenário acadêmico da revista, tanto em âmbito nacional ou internacional, permitirá ter mais ou menos acesso às pessoas do campo acadêmico específico do periódico,l assim como ser reconhecido e legitimado perante os pares (Mehra et al, 2006).

Ante ao que foi exposto em relação ao ambiente institucional e à inserção em redes, é proposto que a internacionalização dos periódicos na área de administração é dependente da resposta articulada a essas duas variáveis, tal como exposto na figura 1 . O pressuposto defendido no artigo é o de que uma revista mais propensa à internacionalização é aquela que tem uma percepção de forte pressão institucional e que está fortemente inserida na rede externa. 


\section{PERCEPÇÃO DO AMBIENTE INSTITUCIONAL}

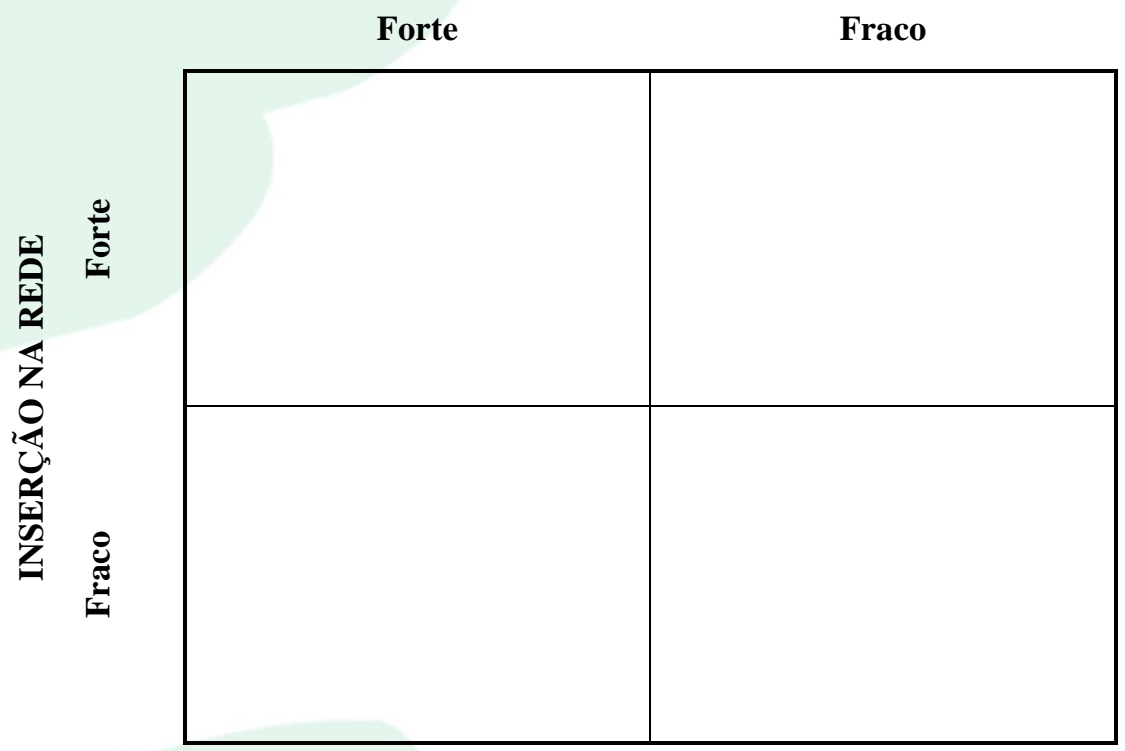

Figura 1 - Percepção do ambiente institucional versus inserção na rede Fonte: Elaborado pelos autores

\section{METODOLOGIA}

Tendo em vista o objetivo deste trabalho, foi adotada a abordagem qualitativa. Entre as várias estratégias praticáveis/possíveis na investigação qualitativa, a estratégia selecionada foi o estudo de caso. Como técnica de coleta de dados, foi utilizada a análise documental das informações das revistas dispostas em seus sites e a entrevista semiestruturada. Seguindo a sugestão de Richardson et al (1999), esse roteiro foi previamente testado com dois pesquisadores que também exercem a função de editores científicos. $\mathrm{O}$ roteiro de entrevista final foi aplicado para seis editores de revistas, cada entrevista durou, em média, 40 minutos, que foram gravadas e transcritas para análise posterior. Três editores solicitaram o anonimato, autorizando somente a gravação. Sendo assim, foi mantido o anonimato do nome de todos os editores e dos nomes das respectivas revistas, a identificação deu-se somente por meio dos seguintes símbolos: X1, X2, X3, X4, X5 e X6. O roteiro de entrevista é composto por três blocos descritos na seguinte forma:

$1^{\circ}$. - Questões relacionadas ao ambiente de redes: Como a revista faz para atrair autores, pareceristas e membros para o conselho editorial internacional? Quais são as principais dificuldades para atraí-los? Em relação aos membros internacionais, qual é a contribuição destes junto à revista? No total de submissões, quantos trabalhos são de outra nacionalidade? No total de artigos publicados, quantos são de outra nacionalidade? O número de submissões e de artigos publicados é um número crescente, ou estagnado? Existe alguma concentração em relação à região? A revista possui estudos bibliométricos, para identificar se os autores que publicam na revista pertencem a alguma rede de pesquisa internacional? A revista possui levantamento para avaliar se os autores brasileiros publicam com pesquisadores internacionais? Como é a parceria da revista com eventos para atrair artigos (exemplo na condição de fast track)? A revista participa de quais eventos nacionais e internacionais? Como se deu essa parceria? Quais são esses eventos? Em quais países?;

$2^{\circ}$. - Questões relacionadas ao ambiente institucional: A revista é vinculada a algum programa de pós-graduação stricto sensu? Qual? Na sua opinião, a revista vinculada ao programa de pós-graduação ajuda no processo de internacionalização da revista? Ou, no sentido contrário, uma revista internacionalizada contribui para internacionalizar o programa de pósgraduação? O programa de stricto sensu exerce influência nos rumos da revista? Em caso positivo, como? Como você seleciona as bases para indexar a revista e o que tem sido feito para o ingresso da revista nestas bases? Quais são as motivações que 
levam a revista a buscar a internacionalização? $\mathrm{Na}$ sua opinião, os critérios de avaliação e de estratificação da Capes conduzem à internacionalização dos periódicos brasileiros? Por quê? A revista tem intenção de publicar artigos em outros idiomas que não seja o português? Como a revista imagina fazer isso?

$3^{\circ}$. - Questões relacionadas a gestão da internacionalização do periódico: A revista é financiada por alguma agência de fomento? Em caso positivo, qual? A revista encontra dificuldades para obtenção de recursos financeiros junto às agências de fomento? Em caso positivo, quais? E o que tem sido feito para amenizar tais dificuldades? Os recursos obtidos são destinados para quais ações na revista? Em caso de não ser financiada por agências de fomento, com quais recursos a revista é mantida? Em um contexto de internacionalização, a revista tem a intenção de mudar de nome? Em caso positivo, qual? Em um contexto de internacionalização, a revista pensa em mudar o layout? Existe alguma inserção da revista nas redes sociais? Em caso positivo, qual? A revista utiliza recursos de altimetria? $\mathrm{Na}$ sua opinião, o que acontecerá com as revistas brasileiras que não se internacionalizarem?

O processo de seleção dos periódicos estudados obedeceu a construção de um corpus de pesquisa (Bauer e Aarts, 2002). Dado o objetivo deste estudo, que é compreender os esforços que as revistas vêm depreendendo para ingressarem no contexto internacional, optou-se por estudar aquelas que estão classificadas nos estratos B1 e B2, visto que grande parte dessas revistas já cumpriu as regras relativas à técnica e normatização, e por isso passam a se preocupar com o ingresso em bases internacionais. Conforme os critérios de estratificação do webqualis, entende-se que revistas classificadas no estrato $\mathrm{A} 1$ ou $\mathrm{A} 2$ são aquelas que obedecem a todos os critérios de estratificação, sendo indexadas nas principais bases internacionais, tais como ISI-Thompson e Scopus, e com os respectivos indicadores bibliométricos JCR e Hindex (Scopus), ou seja, são revistas que apresentam determinado grau de internacionalização, não sendo, portanto, o objeto de interesse para esta investigação. Revistas no estrato B3 ou abaixo ainda estão no processo de cumprimento das etapas relativas à normatização e inserção em bases de dados, distantes da possibilidade de ingressar em um processo de internacionalização.

Considerando o total de seis revistas selecionadas, as entrevistas foram assim encaminhadas: três foram realizadas pessoalmente, duas por meio de skype, e uma, em razão de o editor estar fora do país, foi realizada por e-mail. Dada a solicitação de anonimato, foi mantido em sigilo o nome do editor, da revista e o vínculo institucional. Na figura 2, são apresentadas as revistas que participaram do estudo por meio do símbolo que foi designado, conforme descrito anteriormente, também o seu vínculo institucional (se a revista está atrelada a uma IES ou associação), estratificação e forma da entrevista.

\begin{tabular}{|c|c|c|c|}
\hline Revista & Estrato & Vínculo Institucional & Forma da entrevista \\
\hline Revista X1 & B1 & IES - Privada & Pessoalmente \\
\hline Revista X2 & B1 & Associação profissional & Pessoalmente \\
\hline Revista X3 & B1 & Associação de pesquisadores & Respostas por e-mail \\
\hline Revista X4 & B2 & IES - Privada & Pessoalmente \\
\hline Revista X5 & B2 & IES - Privada & Skype \\
\hline Revista X6 & B2 & IES - Pública & Skype \\
\hline
\end{tabular}

Figura 2 - Perfil das revistas selecionadas para pesquisa

Fonte: Elaborado pelos autores

A técnica de tratamento realizada após a coleta de dados foi a análise do conteúdo (Bardin, 2002). A referida técnica consiste em

$$
\begin{aligned}
& \text { [...]um conjunto de } \\
& \text { técnicas de análises de } \\
& \text { comunicações, que utiliza }
\end{aligned}
$$

procedimentos

sistemáticos e objetivos de descrição do conteúdo das mensagens. A intenção da análise do conteúdo é a inferência de conhecimentos relativos às condições de produção 
e de recepção das mensagens, inferência esta que recorre a indicadores quantitativos ou não (Bardin, 2002, p. 34).

Para Berger (2011), a inferência se materializa por meio de um "[...]sistema de classificação e descrição do conteúdo da comunicação de acordo com categorias prédeterminadas. A técnica requer que as categorias de classificação e análises sejam claras e operacionalmente definidas." (livre tradução -p. 205 e 206).

Bardin (2002) informa que essas categorias são constituídas a partir de "[...] unidades de codificação" ou "de registro", significa dizer que são esses os elementos que proporcionarão significação à mensagem. Tais elementos podem ser compostos por: temas, palavras, sentença, expressão (Bardin, 2002; Franco, 2007). Para tanto, foram usadas as categorias acerca da internacionalização da revista, ambiente de redes e ambiente institucional, veja na figura 3. Essas categorias foram elaboradas com base no referencial teórico a respeito da percepção do ambiente institucional e dos relacionamentos interoganizacionais. Desse modo, a análise dos dados foi baseada nessas categorias, buscando, sempre que possível, o cruzamento das respostas dos entrevistados com os documentos acessados, que eram as informações públicas dos periódicos ou vice-versa, como muitos desses dados públicos já tinham sido coletados antes da entrevista, a pergunta era mais no sentido de entender e esmiuçar aquela informação.

\begin{tabular}{|c|c|c|}
\hline CATEGORIA 1 & CATEGORIA 2 & CATEGORIA 3 \\
\hline Internacionalização da revista & Redes & Ambiente institucional \\
\hline Subcategorias & Subcategorias & Cubcategorias \\
\hline Atividades inerentes à revista & Rede de relacionamento do editor & Indexação \\
\hline Equipe editorial & $\begin{array}{c}\text { Ações para atrair autores } \\
\text { internacionais }\end{array}$ & Fator de impacto \\
\hline Financiamento & Eventos & Estratificação \\
\hline Benchmarking & $\begin{array}{c}\text { Membros do conselho editorial } \\
\text { internacional }\end{array}$ \\
\hline Boas Práticas - Anpad & $\begin{array}{c}\text { Publicação de autores internacionais } \\
\text { Infraestrutura }\end{array}$ & Parcerias internacionais \\
\hline Público-alvo da revista & $\begin{array}{c}\text { Pesquisadores com respaldo } \\
\text { vinculado à revista }\end{array}$ & $\begin{array}{c}\text { Influências submetidas em razão de } \\
\text { seu vínculo }\end{array}$ \\
\hline
\end{tabular}

Figura 3 - Categorias e subcategorias da análise de conteúdo

Fonte: Elaborado pelos autores

\section{RESULTADOS}

A figura 4 apresenta um sumário da análise de cada caso, conforme as categorias e subcategorias da análise de conteúdo

Antes da consolidação das entrevistas, havia uma determinada percepção no que diz respeito ao grau de internacionalização de cada revista. Essa percepção era traduzida na categorização dos periódicos em dois grandes blocos. A primeira categoria, designada às revistas no estrato B1 (sendo o caso das X1, X2 e X3), com status de periódicos mais internacionalizados. A segunda categoria, com revistas no estrato B2 (X4, X5 e X6), com o status de menos internacionalizado. 
Entretanto, após consubstanciar as entrevistas com os editores, essa percepção foi alterada reunindo as revistas em três blocos:

$$
\text { Revistas em processo de }
$$
internacionalização - Aplica-se às revistas X1 e $\mathrm{X} 2$. Estas estão indexadas nas principais bases internacionais (X1: ISI-Thompson e Scopus; X2: Scopus). Além de se constatar ações com o objetivo de se aumentar a sua inserção global.

Revistas não-internacionalizadas, mas com o objetivo de se internacionalizar Identificado nas revistas X3 e X4. Embora não haja ações visando a internacionalização, identifica-se, na fala do editor, a tentativa de negociação junto as mantenedoras para angariar recursos com o objetivo de traduzir artigos. Há no discurso dos editores (principalmente da X4), a preocupação de buscar os indexadores internacionais, bem como inserir a revista em um contexto global (sinalizado pelo editor da X3).

Revistas não-internacionalizadas (sem o objetivo de internacionalizar) - Detectada nas revistas X5 e X6. Ainda que essas revistas sejam classificadas no estrato B2, os editores declararam que não há intenção de internacionalizar a revista.

\begin{tabular}{|c|c|c|c|c|c|c|c|c|}
\hline & \multicolumn{5}{|c|}{ CARACTERÍSTICAS } & \multicolumn{3}{|c|}{ CATEGORIAS } \\
\hline Revista & 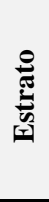 & 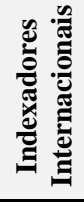 & 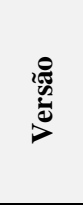 & 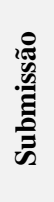 & 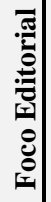 & $\begin{array}{l}\text { Gestão e práticas } \\
\text { científicas }\end{array}$ & Redes & Institucional \\
\hline $\begin{array}{c}\text { Revista } \\
\text { X1 }\end{array}$ & $\bar{n}$ & 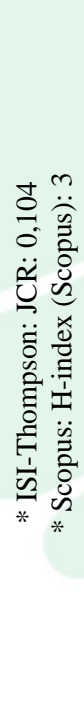 & 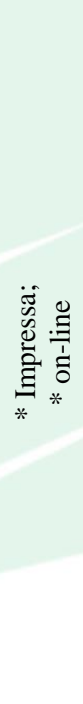 & 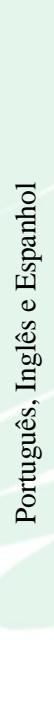 & 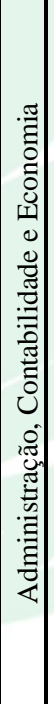 & $\begin{array}{c}\text { * Zelar pela qualidade do } \\
\text { processo editorial desde o } \\
\text { desk review até a decisão } \\
\text { editorial; } \\
\text { * Prazo de resposta longo } \\
\text { considerado como rigor no } \\
\text { processo de avaliação; } \\
\text { * Financiamento: Mantida } \\
\text { pela IES vinculada, } \\
\text { agência de fomento CNPq; } \\
\text { * Internacionalização: } \\
\text { existe ações com o } \\
\text { objetivo de } \\
\text { internacionalizar a revista. }\end{array}$ & $\begin{array}{l}\text { * Editor como ator } \\
\text { principal da revista; } \\
\text { * Ações com vistas a atrair } \\
\text { autores internacionais; } \\
\text { * Preocupação em atrair } \\
\text { autores, pareceristas e } \\
\text { membros para o conselho } \\
\text { editorial internacional; } \\
\text { * Participação em } \\
\text { congressos nacionais; } \\
\text { * Rede de terceiros. }\end{array}$ & $\begin{array}{c}\text { * Publicação em inglês } \\
\text { como principal fonte de } \\
\text { internacionalização e } \\
\text { indexação; } \\
\text { * Influências pelo vínculo } \\
\text { institucional se realiza } \\
\text { somente por meio do corpo } \\
\text { editorial; } \\
\text { * Fator de impacto JRC } \\
\text { visto como critério de } \\
\text { visibilidade e qualidade e } \\
\text { implementa medidas com } \\
\text { vistas a aumentá-lo. } \\
\text { * A revista está indexada } \\
\text { nas duas principais bases } \\
\text { ISI Thompson e Scopus; } \\
\text { * A Capes é vista como a } \\
\text { agência que estabelece os } \\
\text { critérios de avaliação. }\end{array}$ \\
\hline $\begin{array}{c}\text { Revista } \\
\text { X2 }\end{array}$ & $\bar{n}$ & 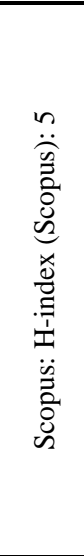 & 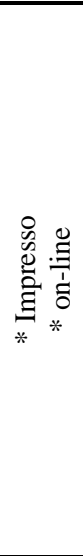 & $\frac{\sqrt{0}}{\stackrel{00}{\Xi D}}$ & 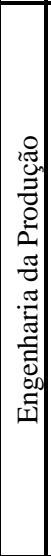 & $\begin{array}{c}\text { * Zelar pela qualidade do } \\
\text { processo editorial desde o } \\
\text { desk review até a decisão } \\
\text { editorial; } \\
\text { * Financiamento: Mantida } \\
\text { pela associação que } \\
\text { mantém a revista, agência } \\
\text { de fomento CNPq e } \\
\text { Fapesp; } \\
\text { * Internacionalização: } \\
\text { existe ações com o } \\
\text { objetivo de } \\
\text { internacionalizar a revista. }\end{array}$ & $\begin{array}{l}\text { * Editor como ator } \\
\text { principal da revista; } \\
\text { * Ações com vistas a atrair } \\
\text { autores internacionais; }\end{array}$ & $\begin{array}{c}\text { * Publicação em inglês } \\
\text { como principal fonte de } \\
\text { internacionalização e } \\
\text { indexação; } \\
\text { * A revista não sofre } \\
\text { nenhuma influência por } \\
\text { parte da associação; } \\
\text { * Os esforços da revista } \\
\text { estão voltados para } \\
\text { ingressar na ISI Thompson } \\
\text { e, consequentemente, no } \\
\text { JRC. Atualmente, a revista } \\
\text { está indexada no Scopus e } \\
\text { possui o indicador SJR. }\end{array}$ \\
\hline
\end{tabular}




\begin{tabular}{|c|c|c|c|c|c|c|c|}
\hline $\begin{array}{c}\text { Revista } \\
\text { X3 }\end{array}$ & $\bar{\infty}$ & $\begin{array}{l}\stackrel{\Xi}{\Xi} \\
\stackrel{\Xi}{\Xi} \\
*\end{array}$ & 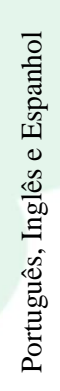 & 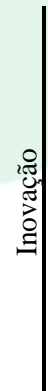 & $\begin{array}{l}\text { * Financiamento: Mantida } \\
\text { pela associação que } \\
\text { financia a revista; } \\
\text { * Internacionalização: não } \\
\text { existe ações com objetivo } \\
\text { de internacionalização. }\end{array}$ & $\begin{array}{l}\text { * Participação em } \\
\text { congressos nacionais. }\end{array}$ & $\begin{array}{l}\text { * Publicação em inglês } \\
\text { como principal fonte de } \\
\text { internacionalização e } \\
\text { indexação; } \\
\text { * A Capes é vista como a } \\
\text { agência que estabelece os } \\
\text { critérios de avaliação; } \\
\text { * Fator de impacto JRC } \\
\text { visto como critério de } \\
\text { visibilidade e qualidade. }\end{array}$ \\
\hline $\begin{array}{c}\text { Revista } \\
\text { X4 }\end{array}$ & $\tilde{\infty}$ & 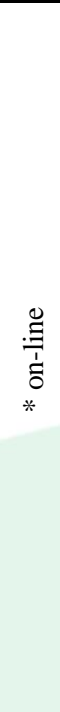 & 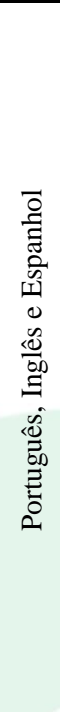 & 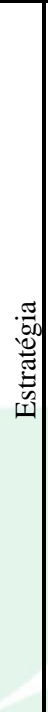 & $\begin{array}{c}\text { * Zelar pela qualidade do } \\
\text { processo editorial desde o } \\
\text { desk review até a decisão } \\
\text { editorial; } \\
\text { * Benchmarking; } \\
\text { * Infraestrutura; } \\
\text { * Equipe editorial; } \\
\text { * Financiamento: Mantida } \\
\text { pela IES vinculada; } \\
\text { * Internacionalização: Não } \\
\text { existe ações com objetivo } \\
\text { de internacionalização }\end{array}$ & $\begin{array}{l}\text { * Editor como ator } \\
\text { principal da revista; } \\
\text { * Preocupação em atrair } \\
\text { autores, pareceristas e } \\
\text { membros para o Conselho } \\
\text { Editorial Internacional }\end{array}$ & $\begin{array}{c}\text { * Publicação em inglês } \\
\text { como principal fonte de } \\
\text { internacionalização e } \\
\text { indexação; } \\
\text { * Indexadores como fonte } \\
\text { de internacionalização; } \\
\text { * As influências de seu } \\
\text { vínculo institucional se } \\
\text { dão por meio do PPG, } \\
\text { que, por sua vez, é regido } \\
\text { pela Capes. }\end{array}$ \\
\hline $\begin{array}{c}\text { Revista } \\
\text { X5 }\end{array}$ & $\widetilde{\infty}$ & $\begin{array}{l}\stackrel{\mathscr{\Xi}}{\leftrightarrows} \\
\stackrel{\Xi}{\Xi} \\
*\end{array}$ & 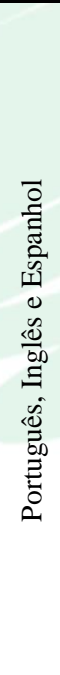 & 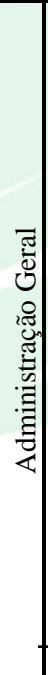 & $\begin{array}{c}\text { * Zelar pela qualidade do } \\
\text { processo editorial desde o } \\
\text { desk review até a decisão } \\
\text { editorial; } \\
\text { * Prazo de resposta longo, } \\
\text { considerado desrespeito } \\
\text { com o autor; } \\
\text { * Benchmarking; } \\
\text { * Financiamento: Mantida } \\
\text { pela IES vinculada; } \\
\text { * Internacionalização: não } \\
\text { existe accões com objetivo } \\
\text { de internacionalizacão }\end{array}$ & $\begin{array}{c}\text { * Editor como ator } \\
\text { principal da revista; } \\
\\
\text { * Participação em } \\
\text { congressos nacionais; } \\
\text { * Possui um estudo } \\
\text { bibliométrico, no entanto, } \\
\text { não com o objetivo de } \\
\text { identificar redes } \\
\text { internacionais. }\end{array}$ & $\begin{array}{c}\text { * Publicação em inglês } \\
\text { como principal fonte de } \\
\text { internacionalização, } \\
\text { entretanto, não objetiva } \\
\text { publica em inglês; } \\
\text { * Critica ao atual sistema } \\
\text { de avaliação; } \\
\text { * Prioriza indexadores } \\
\text { nacionais }\end{array}$ \\
\hline $\begin{array}{c}\text { Revista } \\
\text { X6 }\end{array}$ & $\widetilde{\infty}$ & $\begin{array}{l}\stackrel{\Xi}{\Xi} \\
\stackrel{\Xi}{\Xi} \\
*\end{array}$ & 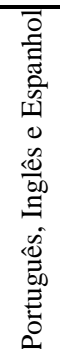 & 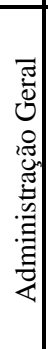 & $\begin{array}{l}\text { * Financiamento: Mantida } \\
\text { pela IES vinculada à Capes } \\
\text { e fundação atrelada à IES; } \\
\text { * Internacionalização: Não } \\
\text { existe ações com objetivo } \\
\text { de internacionalização }\end{array}$ & $\begin{array}{l}\text { * Participação em } \\
\text { congressos nacionais. }\end{array}$ & $\begin{array}{c}\text { * Percebe a indexação } \\
\text { como forma de aumentar } \\
\text { a classificação no web } \\
\text { qualis; } \\
\text { * Pelo fato das revistas } \\
\text { brasileiras não possuírem } \\
\text { fator de impacto, não } \\
\text { desperta interesse por } \\
\text { parte pesquisadores } \\
\text { internacionais. }\end{array}$ \\
\hline
\end{tabular}

Figura 4 - Análise comparativa entre as categorias

Fonte: Elaborado pelos autores 


\section{Categoria Internacionalização da Revista}

Observa-se que, para alcançar determinado grau de internacionalização, a revista deve percorrer várias etapas, a exemplo que foi realizado pelo periódico X1, e, da mesma maneira, enfatizado pelo editor da revista X4. A esse esforço pode-se traçar um paralelo ao gradualismo definido por Johanson e Vahlne (1977) como sendo um conjunto de estágios em que a organização deve cumprir dentro do processo de internacionalização. Entende-se que os estágios percorridos pela revista, antes de alcançar os indicadores bibliométricos, no caso o fator de impacto JCR e H-Index (Scopus), sejam: normatização da revista nos aspectos que contemplam a gestão científica e as práticas científicas; indexação em bases de dados latinoamericanas e indexação em bases de centrais como ISI-Thompson e Scopus.

Independentemente do vínculo institucional, todas as revistas declararam ter dificuldades em relação a questões financeiras, exceto a revista X6. Tais afirmações vão ao encontro do relato da autora Dias (2006), no que diz respeito a um programa de pós-graduação manter uma revista acadêmica. Grande parte das revistas conta com o trabalho voluntariado de pesquisadores e disputa espaço também com outras atividades acadêmicas, além de contar com recursos financeiros restritos. É por esta razão (limitação orçamentária) que iniciativas como ingressar em um processo de internacionalização são inibidas e, por contar em grande parte com trabalho voluntário, a profissionalização da revista pode ser comprometida.

Categoria Ambiente de Redes

No ambiente de redes, o que ficou evidente em quase todas as revistas é a atuação do editor como figura central na condução. Considerando-se que o editor de uma revista científica é também um docente e/ou pesquisador, a sua cadeia de relacionamento pode ser acionada em prol da revista, seja para promover a revista, atrair autores e/ou pareceristas e membros para o conselho editorial, e/ou qualquer outra ação. Há evidências de que os editores das revistas categorizadas como Revistas não internacionalizadas, mas com o objetivo de se internacionalizar têm por fim ultrapassar as fronteiras nacionais tanto dos recursos de redes quanto a estrutura de rede, principalmente quando na fala desses editores é apontada a intenção de participar de congressos e eventos internacionais com a finalidade de maior interatividade no ambiente global, seja para atrair autores, promover o nome da revista, entre vários outros objetivos.

A internacionalização por meio de networks, proposta por Johanson e Vahlne (2009), foi identificada somente no comportamento da revista X1 (entre as seis revistas, esta é que assume uma postura mais internacionalizada). É somente na postura da revista X1 que foi verificado o relacionamento por meio de um processo de bilateralidade, em que as partes envolvidas possam aprender de forma interativa, enfocando $o$ comprometimento mútuo com ênfase na internacionalização, de forma que o conjunto desses relacionamentos leve ao conhecimento e a aprendizagem, desenvolvimento de confiança e oportunidades. Por meio da rede de relacionamento do editor, a revista promove chamadas de trabalhos internacionais e conta com a participação de pesquisadores de renome internacional, ao mesmo tempo, conta com esses pesquisadores no conselho editorial da revista.

\begin{tabular}{|c|c|c|c|}
\hline Redes & $\begin{array}{c}\text { Revistas em processo de } \\
\text { internacionalização }\end{array}$ & $\begin{array}{c}\text { Revistas não- } \\
\text { internacionalizadas, mas } \\
\text { com o objetivo de se } \\
\text { internacionalizar }\end{array}$ & $\begin{array}{c}\text { Revistas sem o objetivo de } \\
\text { internacionalizar }\end{array}$ \\
\hline Estrutura de rede & $\begin{array}{c}\text { Editor como elemento } \\
\text { central }\end{array}$ & Editor como elemento central & $\begin{array}{c}\text { Editor como elemento } \\
\text { central }\end{array}$ \\
\hline $\begin{array}{c}\text { Constituição de redes } \\
\text { internacionais para o } \\
\text { corpo editorial }\end{array}$ & Ação ativa do editor & Ação declarada do editor & Ação passiva do editor \\
\hline Autores internacionais & Baixo para médio & Baixo & Baixo \\
\hline Teia de relacionamento & Pequena em expansão & Pequena & Pequena \\
\hline
\end{tabular}

Figura 5 - Comparativo do ambiente de redes entre as três categorias de revistas

Fonte: Elaborado pelos autores

Em relação ao número de autores internacionais, constata-se que grande destes tem origem institucional entre a Península Ibérica e América Latina. Tais números podem confirmar a 
existência de uma rede ainda regional e uma forte liability of outsidership em relação a rede de pesquisadores internacionais. A análise das entrevistas demonstrou que o aspecto relativo a redes não constata a consolidação de parcerias, sejam elas nacionais ou internacionais, essas ficam restritas a relacionamentos com os prestadores de serviço, qualquer alteração na configuração dessa relação não causará prejuízos. Diferentemente se ocorrer com o editor, pois toda a dimensão de rede está centrada em sua figura, situação que foi apresentada em quase todas as revistas estudadas. A troca deste sem um prévio planejamento e organização, poderá acarretar consequências negativas à revista.

O conjunto de revistas categorizadas como Revistas em Processo de Internacionalização, comparado aos outros dois grupos, é o grupo que concede às redes maior ênfase, buscando expandir internacionalmente pela teia de relacionamento proposta pelo próprio editor, tendo como resultando maior número de autores internacionais. Embora haja grande preocupação por parte dos editores com a internacionalização das revistas categorizadas no segundo grupo, não foi identificada qualquer mobilização para a expansão da teia de relacionamento com vistas à internacionalização ou qualquer outra ação com o mesmo sentido. Pode-se inferir que, quando esse grupo de revistas começou a dar início a tal processo, o investimento em teias de relacionamentos poderá ocupar espaço maior dentro da revista. No terceiro grupo, visto que as revistas não almejam a publicação de autores internacionais, a articulação, por meio da teia de relacionamento, é mínima, visando somente ao público de pesquisadores nacionais.

\section{Categoria ambiente institucional}

Publicar artigos em inglês aumenta a possibilidade de ingressar em bases internacionais, essas, por sua vez, propiciam o acesso aos indicadores bibliométricos mais importantes (JCR do ISI-Thompson e H-Index - Scopus). No entanto, a prioridade em publicar em inglês não é a mesma para as três categorias de revistas, elas se diferenciam conforme apresentado na figura 6 . No primeiro grupo de revista, a publicação em inglês é vista como essencial, seja ela por meio de tradução, como tem sido realizado pela revista $\mathrm{X} 1$, ou, como a revista $\mathrm{X} 2$, decisão de aceitar somente submissões de artigos em inglês. O segundo grupo de revistas, por falta de recursos financeiros, ainda não publica artigos em inglês, contudo, os editores mostram preocupação em disponibilizar tal recurso. No terceiro grupo, os editores consideraram não ser prioridade publicar em inglês.

\begin{tabular}{|c|c|c|c|}
\hline $\begin{array}{c}\text { Ambiente } \\
\text { Institucional }\end{array}$ & $\begin{array}{c}\text { Revistas } \\
\text { Internacionalizadas }\end{array}$ & $\begin{array}{c}\text { Revistas não- } \\
\text { internacionalizadas, mas com } \\
\text { o objetivo de se } \\
\text { internacionalizar }\end{array}$ & $\begin{array}{c}\text { Revistas sem o } \\
\text { objetivo de } \\
\text { internacionalizar }\end{array}$ \\
\hline Idioma & $\begin{array}{c}\text { Preocupação e esforços } \\
\text { efetivos para publicar em } \\
\text { inglês }\end{array}$ & $\begin{array}{l}\text { Em negociação com a } \\
\text { mantenedora para arrecadar } \\
\text { recursos com vistas a } \\
\text { publicação em inglês }\end{array}$ & $\begin{array}{c}\text { Não há esforços para } \\
\text { publicar em inglês }\end{array}$ \\
\hline $\begin{array}{c}\text { Pressão da Capes e } \\
\text { Programa }\end{array}$ & $\begin{array}{l}\text { Percepção entre alta e } \\
\text { média }\end{array}$ & Percepção entre alta e média & $\begin{array}{c}\text { Percepção entre média } \\
\text { e baixa }\end{array}$ \\
\hline Isomorfismo mimético & $\begin{array}{c}\text { Segue o grupo de revistas } \\
\text { internacionalizadas que é } \\
\text { referência na área }\end{array}$ & $\begin{array}{l}\text { Segue o grupo de revistas } \\
\text { internacionalizadas }\end{array}$ & Não sofre essa pressão \\
\hline
\end{tabular}

Figura 6 - Comparativo do ambiente institucional entre as três categorias de revistas

Fonte: Elaborado pelos autores

Na categoria Revistas em Processo de Internacionalizadas, a pressão institucional da Capes e do PPG é vista como sendo entre alta é média, uma vez que, estão nessa categoria revistas como X1 (vinculada a um programa stricto sensu, que, por sua vez, exerce influência na estratificação da revista), e, a revista X2, (vinculada a uma associação profissional). Esta, por sua vez, não exerce influência nos rumos da revista, a postura de internacionalização adotada pela revista parte de uma conduta visionária da própria editoria. Isto significa dizer que é alta para X1 devido à influência de dois fatores, e média para $\mathrm{X} 2$, em função da influência de um fator.

$$
\text { A categoria Revistas não }
$$

internacionalizadas, mas com o objetivo de se 
internacionalizar, segue o mesmo princípio da categoria anterior. Nesse grupo, estão a revista X3, (vinculada a uma associação de pesquisadores, que não exerce influência nos rumos da revista) e a revista $\mathrm{X} 4$, vinculada a um PPG (exercendo grande influência na classificação da revista). Neste caso, a pressão institucional da Capes e do PPG também é vista entre alta e média.

$\mathrm{Na}$ categoria Revistas sem o objetivo de internacionalizar, entende-se que a pressão institucional nessas revistas é considerada entre média e baixa. Nesta categoria, estão as revistas X4 (vinculada a uma IES, no entanto, não oferece pósgraduação stricto sensu) e a revista X5 (vinculada a um PPG) cuja nota deste programa junto a Capes é alta. Como é um programa bem classificado e tem outras revistas, a revista analisada deixa de ser um canal para elevar a nota do programa.

Outro aspecto presenciado no mercado editorial ao qual se pode traçar um paralelo ao ambiente institucional é o conceito de isomorfismo mimético. Tanto a primeira categoria de revistas quanto a segunda, por perceberem, em parte, a pressão institucional como alta, procuram copiar o grupo de revistas bem-sucedidas, seja pelo alto fator de impacto ou a classificação na web qualis (uma vez que essas revistas foram legitimadas por órgãos competentes, tais como a ISI-Thompson ou Capes), dessa forma, permitindo que a revista otimize o tempo, bem como os recursos e investimentos. Observa-se que as revistas estudadas não tomam como referência somente uma revista, pois, ao fazê-lo, perde-se de vista o conjunto de ações praticadas por diversas outras revistas de sucesso e que poderiam contribuir para as revistas em questão. O terceiro grupo de revistas, por perceberem como baixa a pressão institucional, não se vê compelido a buscar as melhores práticas.

\section{DISCUSSÃO DOS RESULTADOS: AMBIENTE INSTITUCIONAL E AMBIENTE DE REDES}

Nesta seção, pretende-se elaborar uma análise comparativa entre as duas principais vertentes teóricas deste trabalho denominadas como Teoria de Redes e Institucionalismo. A análise foi elaborada a partir da matriz, na qual se visualiza graficamente a percepção do editor em relação ao ambiente institucional e a inserção das revistas no ambiente de redes, conforme apresentado na figura 7.

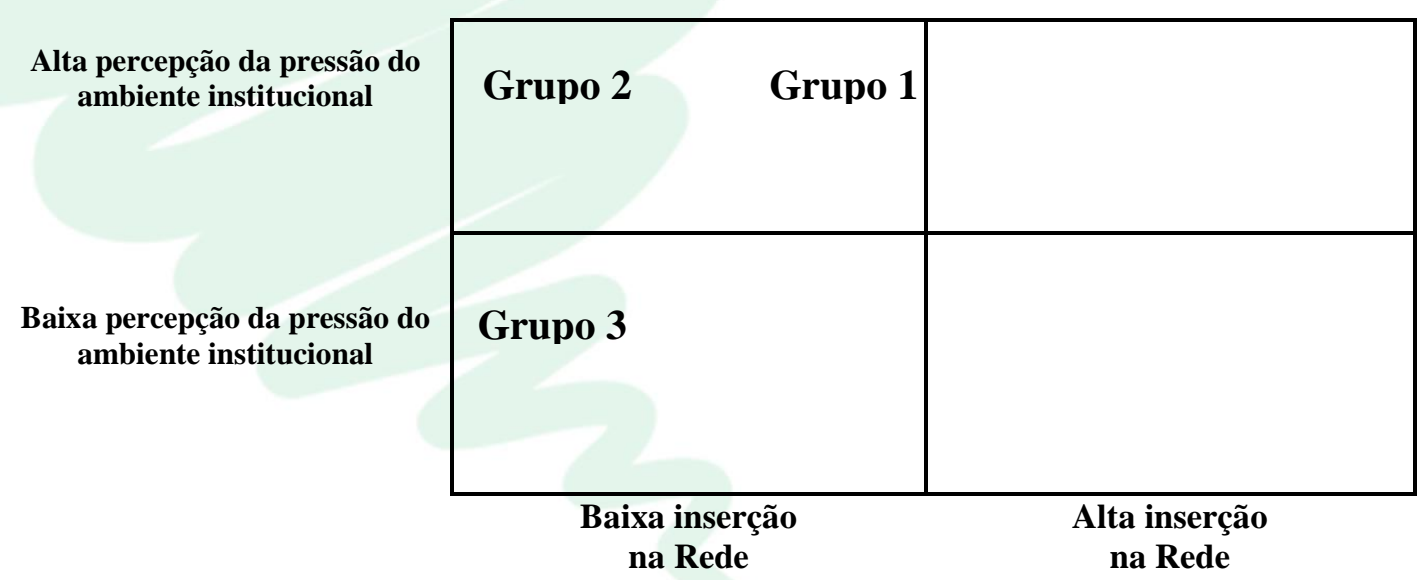

Figura 7: Matriz percepção da pressão do ambiente institucional vs inserção nas redes Fonte: Elaborado pelos autores

Para uma melhor visualização, as categorias de revistas foram representadas por grupos descritas da seguinte maneira: Grupo 1 Revistas em Processo de Internacionalização; Grupo 2 - Revistas não-internacionalizadas, porém, a curto ou médio prazo, pretendem iniciar o seu processo de internacionalização e, por último, Grupo 3 - Revistas sem o objetivo de internacionalizar.

Observa-se que a percepção do ambiente institucional é preponderante para os três grupos de revistas, isto independentemente do seu interesse no ambiente global. A percepção das revistas do grupo 1 e 2 está em um grau mais elevado do que as revistas do grupo 3. Tal preponderância pode ser explicada pela presença da Capes na classificação das revistas e na influência que exerce nos PPGs. Entende-se que até mesmo os periódicos que não estão sujeitos à pressão dos programas, visualizam nas normas da Capes uma forte pressão institucional. Este trabalho não contempla se a discussão dos critérios de avaliação é condizente ou 
não com a realidade nacional e sim buscar o entendimento de quais são os meios que as revistas vêm buscando para superar esses critérios.

Em relação à inserção nas redes, nota-se que os três grupos estão localizados no quadrante de baixa inserção, com destaque para grupo 1 de revistas que demonstrou esforço para internacionalizar-se e apresentou tendência para o quadrante de alta inserção. É possível inferir que o grupo 2, ao iniciar o seu processo de internacionalização, invista na ampliação na teia de relacionamentos.

Uma vez analisado a internacionalização dos periódicos pela ótica do ambiente institucional e redes, é o momento de retomar os objetivos do artigo. Em primeiro lugar, observar os desafios da internacionalização para os periódicos científicos. Nesse âmbito, ficou evidente a forte pressão do ambiente institucional do país de origem, porém a falta de uma macroestratégia institucional para posicionar os periódicos brasileiros no ambiente internacional, assim como a pouca preparação das revistas, para tanto, embora, exista a forte pressão da Capes e, consequentemente, da comunidade acadêmica representada pelos PPGs, os esforços são somente no país de origem, ou seja, não é dada atenção para a questão da desvantagem de ser estrangeiro. Não se enxerga nem nas macropolíticas da Capes e dos PPGs uma preocupação em posicionar as revistas no ambiente internacional. $\mathrm{O}$ que a política atual promove é que as revistas brasileiras devam competir pelos autores das revistas internacionais já consolidadas, porém pouco se pergunta a respeito do diferencial do periódico brasileiro no exterior e como vão superar a desvantagem de ser estrangeiro. Do lado, dos editores, esses, quando pressionados, ficam com a responsabilidade de internacionalizar a revista. Contudo, do mesmo modo, observa-se a ausência de uma estratégia articulada para diferenciar a revista e superar a desvantagem de ser estrangeiro. Também, é quase sempre ausente uma estratégia clara e formal, não centrada somente no esforço do editor, de como a revista poderia se inserir na rede acadêmica internacional para superar a desvantagem de não fazer parte dela. Em suma, o grande desafio da internacionalização dos periódicos da área de administração está na ausência de uma estratégia articulada das instituições do país de origem (Capes, PPGs e periódicos) para (1) conduzir a profissionalização estratégica dos periódicos, (2) se posicionar internacionalmente e (3) superar as desvantagens de ser estrangeiro e de não pertencer a rede internacional.

No segundo momento, quando dá certo a revista decide se internacionalizar, o desafio se estabelece no campo pragmático, pois, no que concerne à gestão do periódico, identificou-se que toda atividade da revista, seja ela científica ou administrativa, está concentrada na figura do editor, assim como toda a cadeia de relacionamento está vinculada a ele. Como consequência, na eventualidade de mudança na direção do periódico, corre-se o risco de que todo o aparato que fornece suporte à revista se perca. Desse modo, emerge do estudo a recomendação às IESs ou associações que mantêm revistas acadêmicas de fomentar a criação de ferramentas com foco na Gestão de Conhecimento, de forma que o know how adquirido ao longo do tempo, fique com a revista e não se dilua na eventual troca de gestor. Todavia, antes de se articular sobre ferramentas de gestão e profissionalização, é necessário refletir sobre formas de financiamento alternativas, visto que este estudo identifica a limitação dos recursos financeiros como uma das maiores dificuldades de se iniciar o processo de internacionalização.

Do desafio proporcionado pela intersecção da análise institucional e de redes, emerge questões teóricas a respeito da internacionalização das organizações. Muito se discute a respeito da desvantagem de ser estrangeiro e de não pertencer a rede, porém pouco se discute a respeito da pressão institucional exercida pelas instituições do país de origem e da própria organização, quando tratamos da internacionalização de uma unidade de negócio da organização. A aferição dos resultados nos remete a reflexão do quanto as pressões por internacionalização são, por vezes, desarticuladas. Muitas vezes, o movimento de internacionalização decorre de uma decisão da cúpula organizacional, ou por resultado de um estímulo do ambiente externo nacional ou internacional, ou, ainda, em decorrência da pressão exercida pelo país de origem, ou mesmo, por uma estratégia de mimetismo em relação aos demais concorrentes. Isso sem dúvida levanta questões do imperativo da internacionalização. A existência de pressões institucionais dos países de origem deve ser melhor investigada para entender $\mathrm{o}$ processo de internacionalização das empresas, assim como, explicar a razão do sucesso ou fracasso ante as desvantagens de ser estrangeiro. Por vezes, a preocupação de superar as desvantagens acontece de forma isolada por parte da empresa e quando o processo de internacionalização já está em curso, quando na verdade, o que os casos analisados relatam, e que a melhor maneira de superar as desvantagens estaria na articulação de uma macroestratégia empresarial e institucional. As premissas institucionais dos países de origem que impulsionam a internacionalização de suas organizações exercem impacto nas estratégias de 
superação das desvantagens de ser estrangeiro e participar da rede, a tal ponto que, o processo de internacionalização, quando pensado de forma articulado, entre instituições e empresas conduziria, a uma internacionalização articulada centrada nas organizações que detém diferencial para vencer no mercado internacional.

A ausência dessa macroestratégia articulada entre instituições e empresas já foi assistida no Brasil. A onda de internacionalização das empresas brasileiras da última década foi fruto da iniciativa organizacional isolada, ou fruto isolado das instituições em promover as campeãs nacionais. $\mathrm{O}$ resultado é a inserção, ainda tímida, e duvidosa, do investimento brasileiro no exterior. $\mathrm{O}$ mesmo erro parece se repetir para os periódicos, alguns se aventuram isoladamente, enquanto outros foram conclamados como campeões nacionais. Parece que a história se repete.

\section{CONSIDERAÇÕES FINAIS}

O objetivo deste estudo consistiu em explicar, à luz da teoria institucional e da teoria de redes sociais, o fenômeno da internacionalização de periódicos científicos brasileiros, na área da Administração de Empresas. Mesmo considerando o número de entrevistas e a subjetividade dos pesquisadores como possíveis limitações deste estudo, o procedimento qualitativo foi cumprido e a amostragem da pesquisa considerada adequada para a pergunta de pesquisa, de modo que os resultados indicam uma postura afirmativa diante do principal pressuposto deste trabalho: as revistas com alta percepção do ambiente institucional e que buscam uma forte inserção nas redes são aquelas mais propensas a se internacionalizar. Ainda que a inserção nas redes não seja alta, a exemplo do que foi constatado no grupo 1 (Revistas em Processo de Internacionalização), estas, por sua vez, apresentam uma forte percepção do ambiente institucional; por outro lado, é o único grupo que demonstra ascensão para o quadrante de inserção nas redes, buscando o seu ingresso global por meio dos recursos de redes.

Em pesquisas futuras, sugerem-se estudos positivistas que investiguem a intenção dos periódicos nacionais em internacionalizar-se; suas necessidades de recursos e a viabilidade econômica da abertura de linhas de crédito à internacionalização de periódicos, por parte da Capes e das demais autoridades científicas brasileiras.

\section{REFERÊNCIAS}

Alisson, E. (2012) Revistas científicas brasileiras ainda têm baixo impacto internacional. Agência Fapesp [Portal]. Recuperado em 26 de dezembro de 2012, de http://agencia.fapesp.br/16332.

(2013) Revistas científicas de países emergentes aumentam processo de internacionalização. Agência Fapesp [Portal]. Recuperado em 27 de dezembro de 2013, de http://agencia.fapesp.br/18142.

Balkundi, P., Kilduff (2006) The ties that lead: A social network approach to leadership. The Leadership Quarterly, 17 (4), 419-439.

Bardin, L. (2002) Análise de conteúdo. Lisboa: Edições 70.

Bauer, M. W., Aarts, A. (2002) A construção do corpus: um princípio para a coleta de dados qualitativos. Pesquisa qualitativa com texto, imagem e som. Um manual prático. Petrópolis: Editora Vozes.

Berger, A. A. (2011) Media and communication research methods. An introduction to qualitative and quantitative approaches. California: Sage.

Berry, H., Guillén, M. F., Zhou, N. (2010) An institutional approach to cross national distance. Journal of International Business Studies, 41, 1460-1480.

Cavusgil, S. T., Knight, G. A., Riesenberger, J. R. (2010) Negócios internacionais: estratégia, gestão e novas realidades. São Paulo: Pearson.

Contractor, J. F. (2013) "Punching above their weight" The sources of competitive advantage for emerging market multinationals. International Journal of Emerging Markets, 8 (4), 304-328

Costa, T. et al. (2012) Bibliometria e a avaliação da produção científica: indicadores e ferramentas. Artigo apresentado em Actas - Congresso Nacional de bibliotecários, arquivistas $e$ documentalistas, Lisboa, Portugal.

Cuervo-Cazurra, A., Genc, E. M. (2011) Obligating, pressuring, and supporting dimensions of the environment and the nonmarket advantages of developing-country multinational companies. Journal of Management Studies, 48 (2), 441-445. 
Dias, C. G. S. (2006) Periódicos na comunicação científica: produção e difusão de periódicos e panorama dos veículos brasileiros da área de Comunicação na base Qualis. Dissertação de metrado, Escola de Comunicação da Universidade Federal do Rio de Janeiro, Rio de Janeiro.

Dimaggio, P. J., Powell, W. W. (2005) A gaiola de ferro revisitada: isomorfismo institucional e racionalidade coletiva nos campos organizacionais. RAE - Revista de Administração de Empresas, 45 (2), 74-89.

Fiorin, J. L. (2007) Internacionalização da produção científica: a publicação de trabalhos de Ciências Humanas e Sociais em periódicos internacionais. Revista Brasileira de PósGraduação, 4 (8), 263-281.

Franco, M. L. P. B. (2007) Análise do conteúdo. Brasília: Liber Livro Editora Ltda.

Himura, H., Carneiro, J., Alperstedt, G. D., Neto, A. C. (2014) O processo de internacionalização de periódicos nacionais. Rev. adm. contemp, 18 (6): 2-4. Recuperado em 03 de maio de 2015, de http://www.scielo.br/scielo.php?script=sci_artte xt\&pid=S1415$65552014000600002 \& \operatorname{lng}=\mathrm{en} \& n r m=$ iso.

Johanson, J., Mattsson, L. (1988) Internationalization in industrial systems - a network approach. In: Hood, N. e Vahlne, J. (ed.) Strategies in global competition, 287-314, New York: Croom Helm.

Johanson, J., Vahlne, J. E. (1977) The internationalization process of the firm: a model of knowledge and increasing foreign market commitment. Journal of International Business Studies, 8 (1), 23-32.

(2009) The Uppsala internationalization process model revisited: from liability of foreignness to liability of outsidership. Journal of International Business Studies, 40 (9), 14111431.

Kostova, T., Zaheer S. (1999) Organizational legitimacy under conditions of complexity: the case of the multinational enterprise. The Academy of Management Review, 24 (1), 64-81.

Mattos, P. L. C. L. (2008) Nós e os índices - a propósito da pressão institucional por publicação. Pensata. RAE - Revista de Administração de Empresas, 48 (2), 144-149.
Mehra, A., Dixon, A., Brass, D. J., Robertson B. (2006) The social network ties of group leaders: implications for group performance and leader reputation. Organization Science, 17 (1), 64-79.

Meneghini, R. (2012) Publicação de periódicos nacionais de ciência em países emergentes. Educação em Revista, 28 (2), 435-432.

Nascimento, R. P., Salvá, M. N. R. (2013) A política de avaliação da pós-graduação StrictoSensu e o Trabalho Docente: Rumo ao "Produtivismo Acadêmico? Artigo apresentado no Encontro de Gestão de Pessoas e Relações de Trabalho, 4, Brasília, Brasil.

Packer, A. L. (2011) Os periódicos brasileiros e a comunicação da pesquisa nacional. Revista USP, 89, 26-61.

Packer, A. L. (2015) A internacionalização dos periódicos foi tema central da Reunião Anual do SciELO, 4. SciELO em Perspectiva. Recuperado em 03 de maio de 2015, de http://blog.scielo.org/blog/2014/12/16/ainternacionalizacao-dos-periodicos-foi-temacentral-da-iv-reuniao-anual-do-scielo/.

Regalardo, A. (2010) Brazilian science: riding a gusher. Science, 330 (6009), 1306-1312. Recuperado em 01 de novembro de 2013, de http://www.sciencemag.org/content/330/6009/1 306.summary.

Richardson, R. J. et al. (1999) Pesquisa social: métodos e técnicas. São Paulo: Atlas.

Rosa, A. R. (2008) Nós e os índices - um outro olhar sobre a pressão institucional por publicação. Pensata. RAE - Revista de Administração de Empresas, 48 (2), 108-114.

Sandes-Guimarães, L. V. (2013) Gestão de periódicos científicos: um estudo com revistas da área de administração. Dissertação de mestrado, Fundação Getúlio Vargas, São Paulo.

Salomon, R., Wu, Z. (2012) Institutional distance and local isomorphism strategy. Journal of International Business Studies, 43 (4), 343-367.

Scott, W. R. (1995) Institutions and organizations. Thousand Oaks, California: Sage.

Trzesniak, P. (2000) A concepção e a construção da revista científica, Apresentação no Encontro de 
Internacionalização de Periódicos Científicos Brasileiros: Estudo de Caso à luz da Teoria de Redes e da Teoria Institucional.

Editoração Científica e Cultural, 2/ Feira PanAmazônica do Livro, 4, Belém, Brasil.
Plata-Caviedes, T., Córdoba-Salgado, O. A. (2012) Qualidade de conteúdo, o grande desafio para os editores científicos. Revista Colombiana de Psicologia, 21 (1), 57-75. 